\title{
Burnout syndrome in surgeons, surgery residents, and medical students: Prevalence and associated factors
}

\author{
Francisco Revilla-Pacheco ${ }^{1 *}$, Pamela Rodriguez-Salgado ${ }^{1}$, Salvador Manrique-Guzman ${ }^{1}$, \\ Tenoch Herrada-Pineda ${ }^{1}$, and Elvira Llaca-Garcia ${ }^{2}$ \\ ${ }^{1}$ Centro Neurológico, The American British Cowdray Medical Center, Mexico City, Mexico; ${ }^{2}$ Facultad de Bioética, Universidad Anáhuac, State of \\ Mexico, Mexico
}

\begin{abstract}
Objective: The aim of the study was to determine the burnout syndrome's prevalence in surgeons, surgery residents and medical students in a private institution using the Maslach Burnout Inventory and to analyze associated factors related to the presence of this syndrome. Materials and methods: Once approved by the Ethics and Research Committee from our Institution, the Maslach Burnout Inventory was used to identify the presence of burnout syndrome in a sample of 72 physicians at the surgery service. The diagnosis of burnout syndrome was defined as the association of a high level of emotional exhaustion and depersonalization with a low level of professional achievement. Its prevalence was determined and an analysis of demographic factors and bioethical training was performed. The relationship of these factors was examined concerning the syndrome's presence or absence, using Fisher's exact test, Chi-square, and Mann-Whitney U-test. Finally, a logistic univariate and multivariate regression analysis applied. Results: A 65\% (Confidence interval 95\% 54-76) burnout syndrome global prevalence was found. The prevalence found in medical students was $67 \%$, in surgery residents $76 \%$, and in surgeons $45.5 \%$. Statistical significance was found between the absence of the syndrome and bioethics training $(p=0.000)$, presence of burnout syndrome, age (higher risk in young people, $p=0.020$ ), and working hours per week (higher risk in subjects with higher workload $p=0.034$ ). No statistical relationship was observed between the burnout syndrome and the gender or the medical position. Conclusions: High burnout syndrome prevalence was found in the medical population from the department of surgery at our institution. This study suggests that the proper knowledge of bioethical aspects in the practice of medicine is a cardinal element that protects against the development of burnout syndrome. The present study points toward an appropriate bioethics training as a preventive factor of the burnout syndrome.
\end{abstract}

Key words: Burnout syndrome. Maslach burnout inventory. Bioethics. Stress. Surgery. Surgeons.

\section{Introduction}

"Burnout syndrome" is a psychological state clinically defined as emotional exhaustion, depersonalization, and a feeling of decreased personal achievement ${ }^{1-4}$.

Even when it is not restricted only to physicians, it mainly affects people who interact with physically and emotionally disabled people such as nurses, rescuers, volunteers, or social workers ${ }^{5}$.

Several studies demonstrate that a high proportion of physicians experiment stress or burnout syndrome with a negative consequence for themselves, their families, coworkers, and patients ${ }^{5-11}$.
Correspondence:

*Francisco Revilla-Pacheco

E-mail: frevilla@ neurociencias.net DOI: 10.24875/HGMX.19000026

NC-ND license (http://creativecommons.org/licenses/by-nc-nd/4.0/) 
Burnout syndrome can affect a physician's job satisfaction, as well as the quality attention they give $^{12-15}$. The burnout syndrome is much more common to be found in physicians than other diseases as depression, drug abuse, or even suicide ${ }^{16}$.

In health-care personnel, high levels of this syndrome have been reported with prevalence rates from $0 \%$ to $70 \%$; probably specific groups of physicians or health-care providers have different risk susceptibility to develop the syndrome ${ }^{17}$.

Factors leading to burnout syndrome have been widely described $4,13,16,18-20$. The most recognized factors are lack of autonomy, difficulty to find a balance between professional and personal life, excessive administrative duties and large numbers of patients to look after ${ }^{21}$. Recently, specific etiological factors for burnout syndrome have been proposed, such as inadequate management of bioethical aspects in the medical practice ${ }^{22-25}$, length of the medical career ${ }^{12,20,26}$, philosophy of delayed gratification ${ }^{8,20,27}$, and long working hours ${ }^{11,21,26}$.

\section{Objective}

The objective of the study was to determine burnout syndrome's prevalence in a sample of physicians related to the department of surgery (surgeons, surgery residents, and medical students in surgical rotations) and to analyze the factors that are associated with its appearance.

\section{Materials and methods}

\section{Design: A cross-sectional, prevalence study in a single institution}

The study was submitted and approved by the Ethics and Research Committee from our Institution; it complies with the ethical standards of the Helsinki Declaration of 1975 (World Medical Association Declaration of Helsinki) and Ethical Principles for Medical Research involving human subjects. All data obtained were anonymous; no record of the participants whatsoever was obtained.

In a sample of 84 surgeons, surgery residents, and medical students; burnout syndrome was measured using the Maslach Burnout Inventory ${ }^{28-30}$. In agreement with its manual, the presence of the syndrome was defined as the association of high levels of depersonalization and emotional exhaustion, together with low levels of personal satisfaction ${ }^{29}$.

Other individual variables were measured: age, gender, and academic degree. Some variables
Table 1. Demographic data of the 72 subjects included

\begin{tabular}{|l|c|c|}
\hline Age (years) & Mean & Standard deviation \\
\hline $\begin{array}{l}\text { Interval } \\
19-65\end{array}$ & 31.4 & 11.6 \\
\hline Gender & Number & Percentage \\
\hline Female & 27 & 37.5 \\
\hline Male & 45 & 62.5 \\
\hline Medical position & & \\
Student & 9 & 12 \\
Resident & 41 & 57 \\
Surgeon & 22 & 31 \\
\hline
\end{tabular}

previously described associated with burnout syndrome were measured specifically through an anonymous survey: academic knowledge about burnout syndrome (ability to define it correctly), bioethical education (defined as having attended at least one semester to a Bioethics Program, either undergraduate or postgraduate studies), and working hours per week. Objectives of the study, methodology and contact information of the main researcher were included in a brief paragraph of the survey and the inventory; an informed consent was also used to participate in the study.

\section{Twelve subjects declined to answer the questionnaire}

Prevalence was calculated for the whole sample and subgroups. Mean \pm standard deviation, median, and confidence interval $(\mathrm{Cl})$ values were used for continuous variables; absolute values and percentages were used for discrete variables related to demographic data.

To calculate the relationship between clinical parameters and burnout syndrome, Fisher's exact test, or Chisquare test was used for categorical variables and t-test, Mann-Whitney U-test or Kruskal-Wallis for continuous variables; a multivariate logistic regression analysis was applied to identify predictive variables; SPSS software version 19 was used. Statistical significance was determined as $p<0.05$.

The method is graphically described in a flow diagram in figure 1.

\section{Results}

Twelve individuals either did not complete or did not return the survey. Demographical data of the 72 subjects are presented in table 1 ; most of the subjects were 


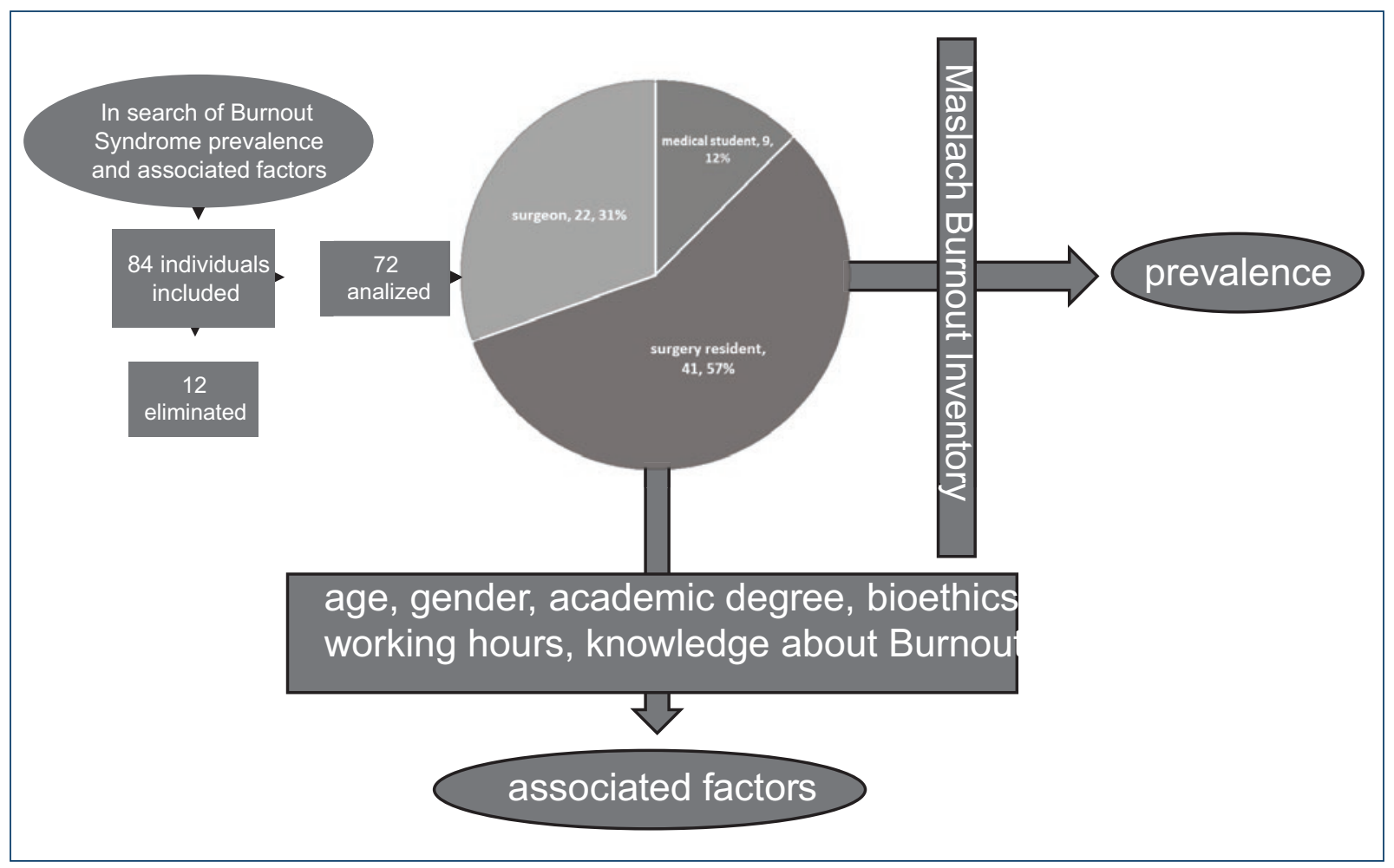

Figure 1. Flow diagram of the methodology of our study.

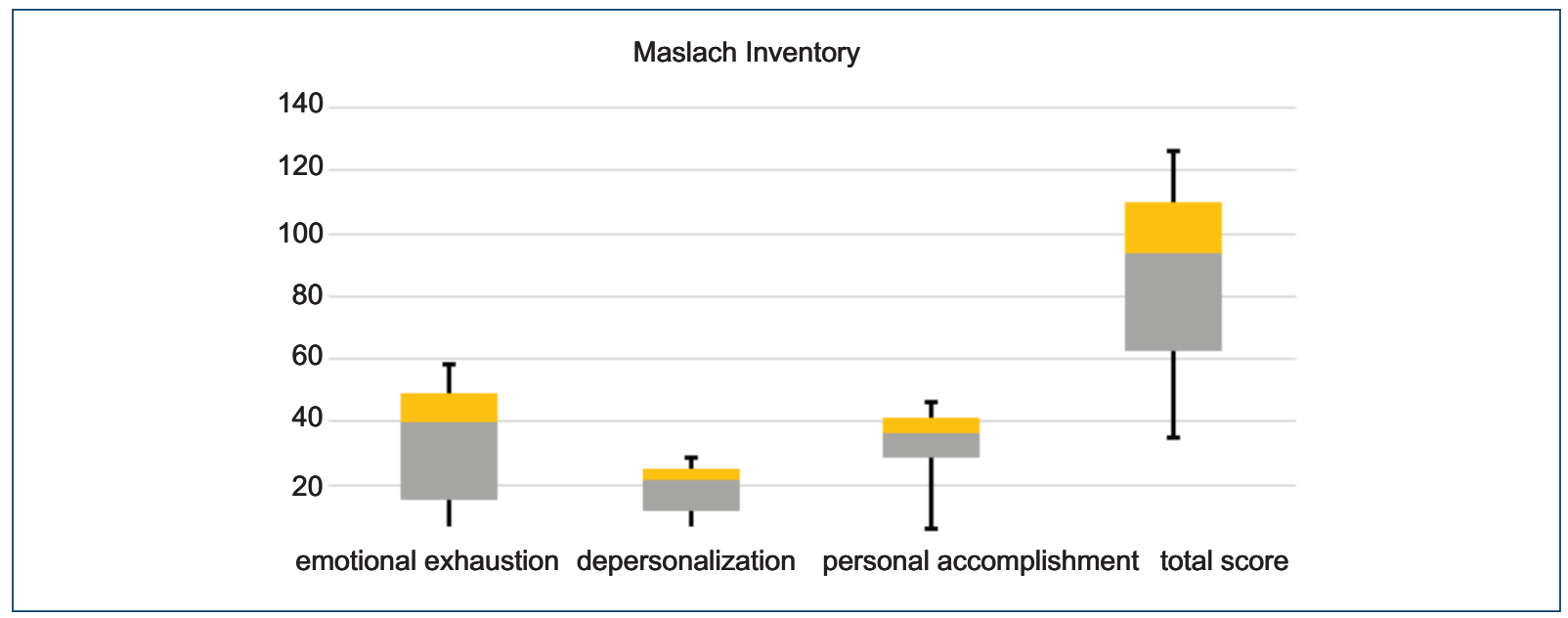

Figure 2. Scores of 72 subjects in the three measurements of Maslach inventory; emotional exhaustion, depersonalization, personal accomplishment, and total score.

surgery residents, least were medical students; and few of them were women.

Figure 2 shows the grades obtained in the 72 subjects within the three measures of the Maslach Burnout Inventory: emotional exhaustion, depersonalization, and personal realization, as well as a total grade ${ }^{28-30}$.

Emotional exhaustion in the Maslach inventory subscale varies from 5 to 54 points. Scores of 27 or more are considered a high level of burnout syndrome, scores between 19 and 26 are considered intermediate levels, and scores under 19 indicate low burnout syndrome levels ${ }^{28}$. In the present study, grades varied from 6 to 54 points and the median was 39.5. Forty-four subjects $(61 \%)$ presented a high level, one subject $(1 \%)$ intermediate level, and twenty-seven (37.5\%) low level. 
Table 2. Comparison between groups with high and mild levels of burnout syndrome, related to variables such as age (mean and interval are shown), gender, medical position, working hours per week, and bioethical training (number and percentage are shown) in 72 subjects studied

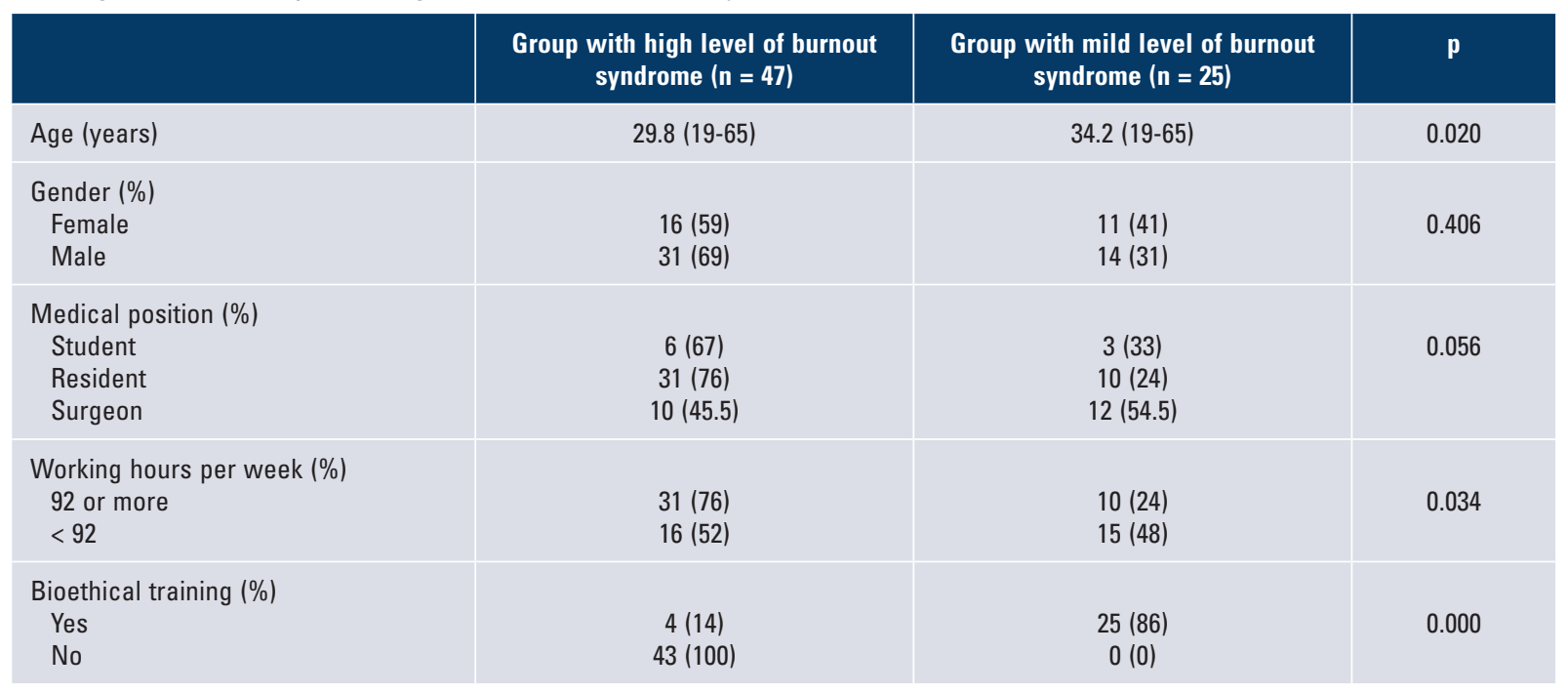

The depersonalization subscale varies from 1 to 30 points. Scores above ten are considered a high level of burnout syndrome, scores between 6 and 9 fit with intermediate levels, and scores under six indicate low levels of this syndrome ${ }^{28}$. In the present study, grades varied from 6 to 30 points, and the median was 21.5. Fifty-nine subjects (82\%) presented a high level and $13(18 \%)$ intermediate level.

On the opposite, the personal accomplishment subscale is inversely proportional to the burnout syndrome level. It varies from 1 to 48 points. Scores above 39 indicate a high level of personal accomplishment and a low level of burnout syndrome. Scores between 31 and 38 indicate intermediate levels, and scores under 31 indicate a high level of burnout syndrome ${ }^{28}$. In the present study, grades varied from 6 to 47 points and the median was 36 . Twenty-three subjects $(32 \%)$ got a high level of personal accomplishment, 30 (42\%) got an intermediate level, and 19 (26\%) got a low level.

The Maslach inventory final grade adds up scores from the three subscales and ranges from 3 to 132 points. It is considered as the gold standard to diagnose burnout syndrome ${ }^{28-30}$. Scores above 67 points indicate a high level of burnout syndrome, scores between 34 and 66 indicate an intermediate level, and scores under 34 indicate a low level of burnout syndrome. In the present study, grades ranged from 35 to 122 points, and the median was 94 . Forty-seven subjects $(65 \%)$ got a high level of burnout syndrome; meanwhile, twenty-five (36\%) got a low level.
In the present study, the global prevalence of burnout syndrome was $65 \%$ (Cl 95\% 54-76). The prevalence in medical students was $67 \%$ (Cl 95\% 36-88), in residents $76 \%(\mathrm{Cl} 95 \% 61-86)$ and in surgeons $45.5 \%(\mathrm{Cl} 95 \%$ 27-66), no significant statistical difference was found between them $(p=0.056)$.

Table 2 shows the results of the 72 subjects related to burnout syndrome and variables as gender, medical position, working hours per week, and bioethical preparation. No significant differences were found between gender or medical position and high or low burnout syndrome levels; however, we certainly found a significant difference between both groups related to age (young subjects are more susceptible to burnout syndrome), working hours per week (subjects with more working hours showed higher susceptibility to burnout syndrome), and bioethical preparation (subjects with no bioethical training were more susceptible to burnout syndrome).

To determine if age and no bioethics training were associated or independent factors, both were analyzed with Chi-square or Fisher's exact test using as independent variables: age, gender, medical position, and working hours per week; and bioethics training as a dependent variable. The results are shown in table 3. No significant difference among groups was found.

Multivariate logistic regression analysis established as risk factors: age under 27 years $(p=0.02)$, more than 92 working hours per week $(p=0.04)$, and lack of bioethics training $(p=0.000)$; as shown in figure 3 . 
Table 3. Comparison between groups with or without bioethical training, related to variables such as age (mean and interval are shown), gender, medical position, and working hours per week (number and percentage are shown) in 72 subjects studied

\section{Group with bioethical training $(n=29) \quad$ Group without bioethical training $(n=43)$}

\section{p}

Age (years)
Gender (\%)
Female
Male
Medical position (\%)
Student
Resident
Surgeon
Working hours per week $(\%)$
92 or more
$<92$

$33(19-65)$

$12(44)$

31 (69)

$3(33)$

$14(34)$

$12(54.5)$

$14(34)$

$15(48)$
$30.2(19-65)$

$15(56)$

$14(31)$

0.577

$6(64)$

$27(66)$

$10(45.5)$

0.261

$27(66)$

$16(52)$

Factors associated with Burnout Syndrome

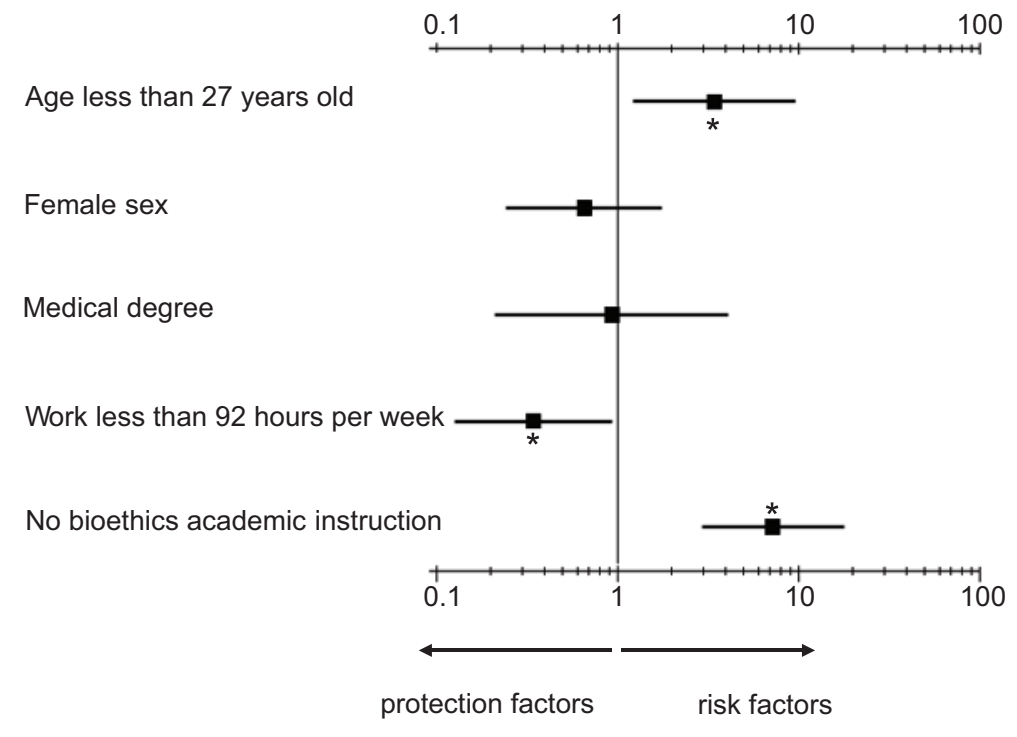

Figure 3. Logistic regression analysis of factors related to burnout syndrome. An asterisk $\left(^{*}\right)$ indicates $p<0.05$; protective factors are found to the left of 1 , risk factors to the right.

\section{Discussion}

Burnout syndrome transcends the affected physician since it is a psychological state where "a complete interest and emotional concern for the patients is lost, considering them as total indifference and even as a dehumanized manner"5.

It is triggered as a response to chronic work stress, and it generally leads to a decrease in adequate patient care, increased medical errors, secondary depression, and drug abuse $e^{18,31,32}$.

Causes of burnout syndrome in physicians have been widely described ${ }^{4,13,16,18,27}$. Conventionally, the main causes of stress have been: lack of autonomy, difficulty to find a balance between personal and professional life, excessive administrative duties, and a large number of patients ${ }^{21}$. The interaction and influence of these factors, together with other working characteristics, form 
a complex phenomenon that affects personal responsibilities, personality, health, and job enthusiasm.

Nowadays, there is a current and renovated interest to identify factors associated to burnout syndrome, among them: weakness related to hierarchical or bureaucratic structures of control that regulate daily clinical practice, inefficient or blocking job politics, lack of material or financial sources to work properly ${ }^{33}$, moral affliction $^{31,32,34-37}$, and ethics issues when making decisions $^{38}$. Besides, an increased interest has been noticed to identify vulnerable populations within medical environment: surgeons ${ }^{7,13,14,39}$, oncologists ${ }^{8,11,40}$, geriatricians $^{41}$, critical care providers ${ }^{31}$, psychiatrists ${ }^{42,43}$, and students and training physicians ${ }^{9,40}$.

Moral, ethical, and bioethical aspects relationship with burnout syndrome have been recently expressed by some authors ${ }^{31,35,36}$, who considered this syndrome as the most negative consequence of moral distress. Moreover, they emphasize the connection of this syndrome with the experience of a patient's death and bioethical influence on making decisions. These authors also notice that "there are no studies speculating about this correlation..."35.

The most important finding of our study is the statistically significant correlation between bioethics training and burnout syndrome $\mathrm{e}^{5,34,37,38}$.

Our research has established bioethical knowledge as a protective factor in burnout syndrome appearance, validating it through a logistic, univariate and multivariate regression analysis, demonstrating a statistical significance between a lack of bioethical preparation and high levels of burnout syndrome (odds ratio $7.25, \mathrm{Cl} 2.9-18, \mathrm{p}=0.000$ ).

A recent manuscript revealed a similar analysis between "moral distress" and burnout syndrome ${ }^{31}$, also finding a positive association ( $p=0.010$ ) between moral distress (defined as the impossibility to act according to a person's values and his/her obligations due to external and internal limitations) and burnout syndrome. Similar to our results, they found that moral distress is independently associated with burnout syndrome appearance (odds ratio $2.4, \mathrm{Cl} 1.19-4.82, \mathrm{p}=0.014$ ).

It has been described that the lack of academic tools necessary to analyze effectively bioethical problems in medicine, is one of the most important reasons to develop chronic stress in residents and surgeons ${ }^{22-25}$. Many reasons exist: a lot of issues in the modern practice of medicine are quotidian dilemmas in physician's duty; decisions about delicate matters should be firmly based in bioethical training and knowledge; and not assigned just to physicians' free will or linked to common morality ${ }^{22}$. Common conflicts related to proper medical attention offered to patients with incurable diseases, such as disagreements about the best treatment alternatives, therapeutic obstination, and decisions in terminal patients, have all been documented as risk factors for developing burnout syndrome ${ }^{44-48}$.

In the present study, in agreement with other reports $8,9,11,40$, it has been found that young physicians $(<29$ years old) are more susceptible to burnout syndrome $(p=0.020)$, not related to their academic degree (no significant difference was found between medical students and surgery residents).

Moreover, the present study showed a statistically significant association between high working hours per week and an increased burnout syndrome level $(p=0.034)$; similar to the previous reports ${ }^{12,20,26}$. Other trials have also found an association with a high working load (number of cases per week) ${ }^{11}$.

Our study has several limitations: its transversal design, the results reported refer to a single population in one institution, which causes homogeneity and lack of randomness in the studied population; circumstances or reasons of the subjects that declined to participate were not examined which represented bias against the study. Its design did not allow us to determine causality.

\section{Conclusions}

About $65 \%$ prevalence of burnout syndrome has been found in a population of physicians of different ages, and academic degrees from the department of surgery. The prevalence found is very high, similar to that reported in other studies related to surgical specialties, which highlight the magnitude of the problem. Even when recognized, very few programs are directed to detect the phenomena, and to the best of our knowledge, no protocols are focused on preventing it in our ambit. Because of its high prevalence and also because of its serious and deleterious consequences, there is a strong need for further research about the subject and its causes.

We have found two main factors associated to higher level of burnout syndrome: age and bioethical knowledge; young doctors independently from its academic degree are more susceptible to develop the phenomena; interestingly, bioethical knowledge is a protective factor in burnout syndrome appearance; the relationship between burnout syndrome and moral, ethical and bioethical aspects has been recently described in medical literature.

Further investigation could validate these findings; meanwhile, we would like to highlight that age of a given person cannot be modified, but bioethical preparation can, so this work could motivate to make adjustments 
to the curricula in medical colleges and residency programs with the added value of giving to young doctors strategies to cope with burnout syndrome.

\section{Conflicts of interest}

Authors declare that they do not have conflicts of interest.

\section{Ethical disclosures}

Protection of human and animal subjects. The authors declare that no experiments were performed on humans or animals for this study.

Confidentiality of data. The authors declare that they have followed the protocols of their work center on the publication of patient data.

Right to privacy and informed consent. The authors have obtained the written informed consent of the patients or subjects mentioned in the article. The corresponding author is in possession of this document.

\section{References}

1. Maslach C, Schaufeli WB, Leiter MP. Job burnout. Annu Rev Psychol. 2001;52:397-422.

2. Squiers JJ, Lobdell KW, Fann JI, DiMaio JM. Physician burnout: are we treating the symptoms instead of the disease? Ann Thorac Surg. 2017; 104:1117-22.

3. Steinmeier R, Rachinger J, Kaus M, Ganslandt O, Huk W, Fahlbusch R. Factors influencing the application accuracy of neuronavigation systems. Stereotact Funct Neurosurg. 2000;75:188-202.

4. Shanafelt TD, Sloan JA, Habermann TM. The well-being of physicians. Am J Med. 2003;114:513-9.

5. Dyrbye L, Shanafelt T, Timbros J, Timbros-Kemper T. Protecting and Promoting the Well-being of Surgeons. Basics of Surgery. Maarssen: Elsevier Gezondheidzorg; 2007. p. 177-84.

6. Green A, Duthie HL, Young HL, Peters TJ. Stress in surgeons. Br J Surg. 1990;77:1154-8.

7. Kent GG, Johnson AG. Conflicting demands in surgical practice. Ann R Coll Surg. Engl. 1995;77:235-8.

8. Shanafelt T. A career in surgical oncology: finding meaning, balance, and personal satisfaction. Ann Surg Oncol. 2008;15:400-6.

9. Campbell DA Jr., Sonnad SS, Eckhauser FE, Campbell KK, Greenfield LJ. Burnout among American surgeons. Surgery. 2001;130:696-702.

10. Harms BA, Heise CP, Gould JC, Starling JR. A 25-year single institution analysis of health, practice, and fate of general surgeons. Ann Surg. 2005;242:520-6.

11. Kuerer HM, Eberlein TJ, Pollock RE, Huschka M, Baile WF, Morrow M, et al. Career satisfaction, practice patterns and burnout among surgical oncologists: report on the quality of life of members of the Society of Surgical Oncology. Ann Surg Oncol. 2007;14:3043-53.

12. Shanafelt TD, Bradley KA, Wipf JE, Back AL. Burnout and self-reported patient care in an internal medicine residency program. Ann Intern Med. 2002;136:358-67.

13. Shanafelt TD, Balch CM, Bechamps G, Russell T, Dyrbye L, Satele D, et al. Burnout and medical errors among American surgeons. Ann Surg. 2010;251:995-1000.

14. West CP, Huschka MM, Novotny PJ, Sloan JA, Kolars JC, Habermann TM, et al. Association of perceived medical errors with resident distress and empathy: a prospective longitudinal study. JAMA. 2006;296:1071-8.

15. Firth-Cozens J, Greenhalgh J. Doctors' perceptions of the links between stress and lowered clinical care. Soc Sci Med. 1997;44:1017-22.

16. Meier DE, Back AL, Morrison RS. The inner life of physicians and care of the seriously ill. JAMA. 2001;286:3007-14.

17. van Mol MM, Kompanje EJ, Benoit DD, Bakker J, Nijkamp MD. The prevalence of compassion fatigue and burnout among healthcare professionals in intensive care units: a systematic review. PLoS One. 2015;10:e0136955.
18. Spickard A Jr., Gabbe SG, Christensen JF. Mid-career burnout in generalist and specialist physicians. JAMA. 2002;288:1447-50.

19. Shanafelt TD, Novotny P, Johnson ME, Zhao X, Steensma DP, Lacy MQ, et al. The well-being and personal wellness promotion strategies of medical oncologists in the North Central Cancer Treatment Group. Oncology. 2005;68:23-32.

20. Shanafelt $T$, Chung $H$, White $H$, Lyckholm LJ. Shaping your career to maximize personal satisfaction in the practice of oncology. $\mathrm{J}$ Clin Oncol. 2006;24:4020-6

21. Balch $\mathrm{CM}$, Shanafelt $\mathrm{T}$. Combating stress and burnout in surgical practice: a review. Thorac Surg Clin. 2011;21:417-30.

22. McCullough LB, Jones JW, Brody BA. Surgical Ethics. New York: Oxford University Press; 1998.

23. Ford PJ, DeMarco JP. Brains, ethics, and elective surgeries: emerging ethics consultation. Ethics Med. 2007;23:39.

24. Breen KJ. Ethics, Law, and Medical Practice. St Leonards: Allen and Unwin; 1997.

25. Pearson SD, Sabin J, Emanuel EJ. No Margin, No Mission: Health Care Organizations and the Quest for Ethical Excellence. New York: Oxford University Press; 2003

26. Dyrbye LN, Thomas MR, Huschka MM, Lawson KL, Novotny PJ, Sloan JA, et al. A multicenter study of burnout, depression, and quality of life in minority and nonminority US medical students. Mayo Clin Proc. 2006;81:1435-42.

27. Shanafelt TD. Finding meaning, balance, and personal satisfaction in the practice of oncology. J Support Oncol. 2005;3:157-62, 164.

28. Maslach C, Jackson SE. The measurement of experienced burnout. J Organ Behav. 1981;2:99-113.

29. Maslach C, Jackson S, Leiter M. The Maslach Burnout Inventory. All Versions of the $\mathrm{MBI}$, and the Manual, are Now Available at Mind Garden. Palo Alto, CA: Consulting Psychologists Press; 1996.

30. Seisdedos N. MBI Inventario Burnout de Maslach. Madrid: TEA Ediciones; 1997.

31. Fumis RR, Junqueira Amarante GA, de Fátima Nascimento $A$, Vieira Junior JM. Moral distress and its contribution to the development of burnout syndrome among critical care providers. Ann Intensive Care. 2017;7:71.

32. Meltzer LS, Huckabay LM. Critical care nurses' perceptions of futile care and its effect on burnout. Am J Crit Care. 2004;13:202-8.

33. Epstein EG, Hamric AB. Moral distress, moral residue, and the crescendo effect. J Clin Ethics. 2009;20:330-42.

34. Rushton $\mathrm{CH}$. Defining and addressing moral distress: tools for critical care nursing leaders. AACN Adv Crit Care. 2006;17:161-8.

35. Corley MC. Nurse moral distress: a proposed theory and research agenda. Nurs Ethics. 2002;9:636-50

36. Elpern EH, Covert B, Kleinpell R. Moral distress of staff nurses in a medical intensive care unit. Am J Crit Care. 2005;14:523-30.

37. Shoorideh FA, Ashktorab T, Yaghmaei F, Alavi Majd H. Relationship between ICU nurses' moral distress with burnout and anticipated turnover. Nurs Ethics. 2015;22:64-76.

38. Teixeira C, Ribeiro O, Fonseca AM, Carvalho AS. Burnout in intensive care units-a consideration of the possible prevalence and frequency of new risk factors: a descriptive correlational multicentre study. BMC Anesthesiol. 2013;13:38.

39. Lichtenstein RL. The job satisfaction and retention of physicians in organized settings: a literature review. Med Care Rev. 1984;41:139-79.

40. Ramirez AJ, Graham J, Richards MA, Cull A, Gregory WM, Leaning MS, et al. Burnout and psychiatric disorder among cancer clinicians. $\mathrm{Br} J$ Cancer. 1995;71:1263-9.

41. Linzitto JP, Grance G. Health professionals' quality of life in relation to end of life care. Curr Opin Support Palliat Care. 2017;11:306-9.

42. Tateno M, Jovanović N, Beezhold J, Uehara-Aoyama K, Umene-Nakano W, Nakamae T, et al. Suicidal ideation and burnout among psychiatric trainees in Japan. Early Interv Psychiatry. 2018;12:935-7.

43. Owczarek K, Wojtowicz S, Pawłowski W, Białoszewski D. Burnout syndrome among physiotherapists. Wiad Lek. 2017;70:537-42.

44. Embriaco N, Papazian L, Kentish-Barnes N, Pochard F, Azoulay E. Burnout syndrome among critical care healthcare workers. Curr Opin Crit Care. 2007;13:482-8.

45. Martins Pereira S, Teixeira CM, Carvalho AS, Hernández-Marrero $P$ InPalln. Compared to palliative care, working in intensive care more than doubles the chances of burnout: results from a nationwide comparative study. PLoS One. 2016;11:e0162340.

46. Bruce CR, Miller SM, Zimmerman JL. A qualitative study exploring moral distress in the ICU team: the importance of unit functionality and intrateam dynamics. Crit Care Med. 2015;43:823-31.

47. Wilson MA, Goettemoeller DM, Bevan NA, McCord JM. Moral distress: levels, coping and preferred interventions in critical care and transitional care nurses. J Clin Nurs. 2013;22:1455-66.

48. Houston S, Casanova MA, Leveille M, Schmidt KL, Barnes SA, Trungale KR, et al. The intensity and frequency of moral distress among different healthcare disciplines. J Clin Ethics. 2013;24:98-112. 